\title{
ESTUDIO DE LAS PIEZAS DENTALES DEL INDIVIDUO N 1 DEL ALERO "ERNESTO MARIFILO-1", REGION DE LOS RIOS, CHILE.
}

\author{
SUSANA MORANO B." Y SANDRA BUCAREY A."
}

\section{RESUMEN}

Entre 1999 y 2001, se realizó el hallazgo del Individuo № 1 en el sitio "Alero Ernesto Marifilo1", al norte del lago Calafquén, Región de Los Ríos, Chile. Este fue fechado en $6.030 \pm 40$ AP. En el presente trabajo, a través de la antropología dental, se pretende interpretar el tipo de vida que tuvo el Individuo № 1, en relación a su estado de salud y dieta, así como su edad en el momento del deceso. Además, se intenta comparar los restos arqueológicos faunísticos y vegetacionales hallados en el sitio con los resultados obtenidos en el análisis de las piezas dentales.

Se determinó su edad mediante el método de erupción dental. Para determinar el estado de salud se utilizaron los parámetros: caries, chipping, desgaste dental, hipoplasia dental, abscesos y retracción alveolar. Para conocer la dieta se utilizó los tres primeros parámetros nombrados anteriormente. Se constató que la salud oral y general del infante fue buena, dado que cada parámetro se manifestó en grados leves. Su dieta se consideró como mixta, con componentes dulceacuícolas, obtenidos del ecosistema donde habitó. Finalmente, estos resultados son concordantes con los obtenidos en los estudios del sitio.

PALABRAS CLAVES: Marifilo-1, Antropología dental, Patologías dentales, Dieta.

\section{DENTAL STUDY OF THE PIECES OF HE INDIVIDUAL №1 OF ROCKSHELTER "ERNESTO MARIFILO-1", REGION DE LOS RIOS, CHILE.}

\footnotetext{
ABSTRACT

Between the years 1999 and 2001, the individual №1 was discovered in the archaeological site "Alero Ernesto Marifilo-1", to the north of Lake Calafquén, region Los Ríos, Chile. The infant was dated in the period 6,030 $\pm 40 \mathrm{BP}$. By means of Dental Anthropology, this work attempts to interpret the type of life that individual №1 had, with respect to the state of health and type of diet, as well as the age at the time of death. In addition, it tries to compare the archaeological remainders of wildlife and vegetation found at the excavation site, with the results obtained from the analysis of the dental structures of the

Centro de Estudios del Hombre Austral, Instituto de la Patagonia, Universidad de Magallanes. Av. Bulnes 01890, Casilla 113D, Punta Arenas, Chile. susana.morano@hotmail.com

* Instituto de Anatomía, Histología y Patología. Facultad de Medicina. Campus Isla Teja, Universidad Austral de Chile. Valdivia, Chile.sbucarey@uach.cl
} 
infant. The age of individual №1 was determined using the method of dental eruption. In order to determine its state of health, the following dental parameters were used: caries, dental hypoplasia, abscesses, chipping, alveolar retraction, and dental wear. Its diet on the other hand, only required the followed parameters: carie, chipping, and dental wear. The oral and general health was good, where each parameter was manifested to a very small extent, and the diet of the infant can be considered mixed, consisting of components such as freshwater, meats and fruits, obtained from the ecosystem where individual № 1 lived. Finally, the results obtained by using Dental Anthropology conform to the results obtained from studies of the archaeological site.

KEY WORDS: Marifilo-1, Dental anthropology, Dental pathology, Diet.

\section{INTRODUCCIÓN}

\section{ANTECEDENTES ARQUEOLÓGICOS.}

Entre los años 1999 y 2001 se realizó la excavación del sitio Alero Ernesto Marifilo-1, en la localidad de Pucura, Región de Los Ríos, Chile. Se trata de un sitio arqueológico, que fue investigado en el marco de los proyectos FONDECYT 1971005 y 1010200, dedicados al estudio de la "Tradición Arqueológica de Bosques Templados en la Zona Centro-Sur de Chile". Este sitio arqueológico se localiza al norte del lago Calafquén, a una altura de $300 \mathrm{~m}$ y a una distancia de $1260 \mathrm{~m}$ de la costa del lago. Además de los muchos restos faunísticos y vegetacionales hallados, se encontraron restos óseos humanos de 3 individuos, uno de ellos el denominado Individuo № 1 , que es utilizado como muestra para este trabajo (Pino et al. 2004).
El hallazgo del Individuo № 1, se realizó en las unidades B-16 y B-17 niveles 70-80 (70$80 \mathrm{~cm}$. de profundidad), localizado cercano a la pared del alero. El cuerpo, dispuesto perpendicular a la pared del alero, se encontraba en posición decúbito lateral derecho (Figura 1). El cráneo distaba $30 \mathrm{~cm}$. de la pared del alero, con su rostro en dirección hacia el sur, que en este caso coincide con la costa del lago. Entre las características del entierro, destaca una quema sobre el cuerpo, específicamente en la región pectoral, lo que carbonizó parte de las costillas y del cráneo del infante. Sobre el fogón se registraron abundantes restos de ceniza y valvas de Diplodon chilensis. Sobre el cráneo, se ubicó un guijarro de granito, usado probablemente como indicador del entierro. La única ofrenda asociada directamente al cuerpo la constituye un sobador lítico (Adán 2003).

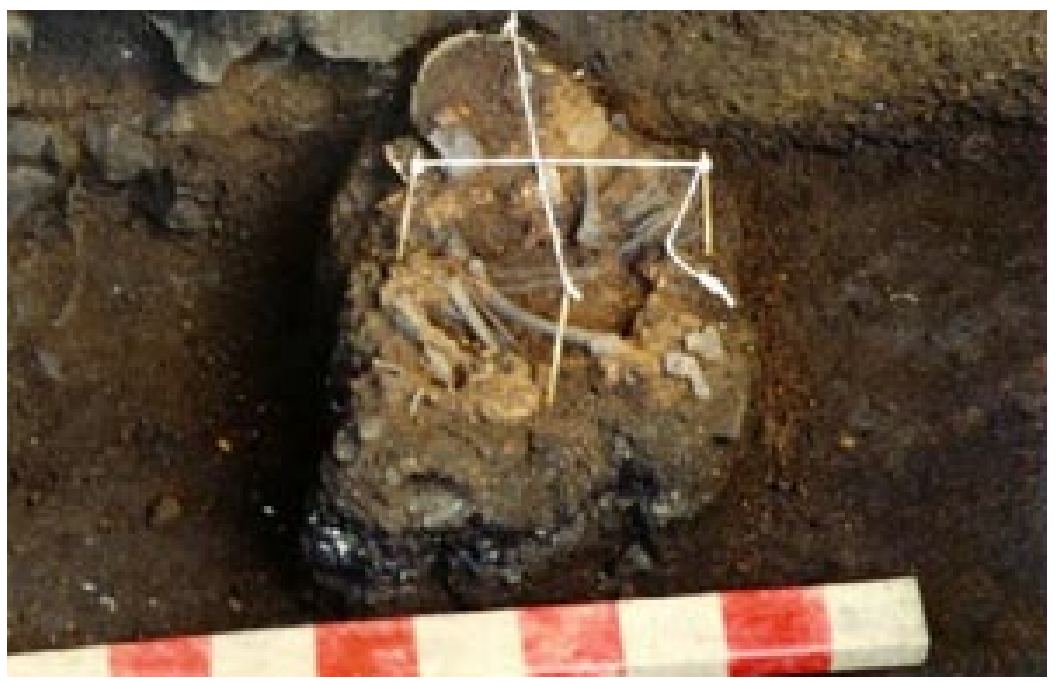

Fig. 1. Individuo $\mathrm{N}^{\circ} 1$. 
La secuencia registrada en Marifilo-1, indica una constante valoración de estos espacios por parte de poblaciones arcaicas y alfareras. Las dataciones obtenidas llenan un vacío en la arqueología local, entre aquellas conocidas para los primeros americanos y las de las adaptaciones costeras hacia los 5.000 AP. La excavación realizada en el sitio, permitió obtener una variedad de restos y objetos hallados. Entre los restos animales se encuentran Pudu pu$d u$, Pseudalopex griseus y Felis guigna; los restos botánicos son representados por Nothophagus sp., Aextoxicon punctatum, Rhapitamnus spinosus, entre otros; dentro de los objetos recuperados se encuentran una espátula-punzón sobre tibia distal de huemul, punzones en ulna de zorro chilla y un artefacto de funcionalidad desconocida en fémur de pudú (Pino et al. 2004).

Este infante fue fechado en $6.030 \pm 40 \mathrm{AP} \mathrm{y}$ este dato se obtuvo de un fragmento de parietal (Pino et al. 2004). Esta fecha lo ubica en el Holoceno y en el período cultural denominado Arcaico Medio, que es representado por grupos de cazadores-recolectores, que se agrupan en bandas, generalmente nómades con ciclo anual de movimiento de acuerdo a las estaciones climáticas, donde los sitios de cobijo son cuevas o abrigos rocosos (Silva 2001).

\section{ANTECEDENTES GENERALES}

La antropología dental es una herramienta útil en la determinación de la edad, raza, dieta, nivel nutricional, estado de salud e impacto del ambiente en un individuo o población. A nivel mundial, las investigaciones en base a las piezas dentales son de mucha importancia y un gran número de publicaciones y libros especializados en el tema lo corroboran. Científicos como Goodmann y Armelagos (1985), han profundizado en el estudio de la hipoplasia de esmalte, de su frecuencia y causales de aparición; por otro lado, Ubelaker (1996), ha enfatizado en las patologías, determinación de la edad, sexo y raza; igualmente Buikstra y Ubelaker (1994), Hillson (1996), Brothwell (1987), han contribuido en gran forma a la difusión y al avance de la antropología dental como ciencia, debido a sus publicaciones de manuales teóricos o de terreno.

En Chile, el estudio de las piezas dentales, como parte del análisis bioantropológico de restos arqueológicos ha ido tomando importancia, como lo demuestran los crecientes estudios llevados a cabo en la zona norte, central y sur de nuestro país. Algunos de los trabajos recientes y donde se utiliza la antropología dental como parte del estudio bioantropológico, son los realizado por Rodríguez et al. (2004), en los restos hallados en la parroquia La Purísima Concepción de Colina, donde se analizaron 14 individuos, en busca de patologías dentales y traumas. Los resultados obtenidos, indican una población con un alto índice de patologías dentales, principalmente caries, que evidencian una dieta blanda y rica en carbohidratos. Por otra parte, el estudio de hipoplasia dental, sugiere un periodo de lactancia breve, que pudo incidir en el desarrollo inmunológico de los individuos. El estudio de Cueva Baño Nuevo1, XI región, realizado por Mena y Reyes (2001), se centró en el análisis dental de 2 individuos adultos, de estos restos se pudo concluir que el excesivo desgaste se produjo por una dieta abrasiva y por el estrés mecánico, a que fue sometida la cavidad oral. Sin existir indicios de estrés nutricional prolongado o episódico, que indicaría un buen desarrollo de los individuos, durante su infancia.

Estudios realizados en la Patagonia por Schinder y Guichon (2003), donde se analizó la dieta de aborígenes de Tierra del Fuego, mediante la técnica de isótopos estables y comparando los datos obtenidos con el estilo de vida de ellos, encontraron que existía tanto dieta terrestre-mixta como dieta netamente marina, lo que influía en el estado de salud de la población. Igualmente Pérez-Pérez y Lalueza Fox (1992), analizaron restos de aborígenes de Tierra del Fuego, ellos por su parte estudiaron los indicadores de presión ambiental, concluyendo que estos grupos humanos poseían una baja incidencia de patología oral, que se debía en parte a una alta ingesta de carne. Estos estudios, más otros realizados desde la década de los 80 hasta la actualidad, han sido posibles gracias al creciente auge de las excavaciones arqueológicas, que han entregado una riqueza de materiales líticos, botánicos, restos animales y humanos.

El interés central de este trabajo, es responder a interrogantes como: la edad del Individuo № 1 al momento de su deceso, el estado de salud de, el tipo de dieta predominante y por ultimo si existe alguna correlación entre los resultados obtenidos en este estudio, con los elementos faunísticos y vegetacionales, encontrados en el sitio arqueológi- 
co Alero Ernesto Marifilo-1. Para esto se utilizó las piezas dentales del Individuo $\mathrm{N}^{\circ} 1$, por ser los restos mejor conservados del infante (Figura 2).

\section{MATERIALES Y MÉTODOS}

Las piezas dentarias analizadas provienen en su totalidad de un infante de sexo y edad indeterminada, correspondiente al Individuo № 1 encontrado en el Alero Marifilo-1, el que fue facilitado para este estudio, por la Arqueóloga Leonor Adán, directora del Museo Histórico-Arqueológico Maurice Van de Maele, dependiente de la Universidad Austral de Chile. La muestra consiste en 27 dientes, 17 de ellos deciduos y los 10 restantes son permanentes. Las piezas dentales que aún se encontraban encerradas en su alvéolo o con la corona en proceso de formación, fueron excluidas de la muestra.

Para determinar la edad del individuo al momento de su deceso, se utilizó el método de la erupción de las piezas dentales descritos por diferentes autores (Schour y Massler 1941; Ubelaker, 1996; Woelfel y Scheid 1998). Esto se complemento con la regla de Black para la reabsorción de las raíces caducas, descritas en Hogeboom (1940). Posteriormente, se confeccionó un registró de piezas dentarias deciduas que no se presentaban, debido al recambio natural de estas y otro registro de piezas permanentes que se encontraban en proceso de erupción al momento de muerte del infante, esto para comparar ambos registros con la tabla de erupción de Schour y Massler (1941). Por último se confeccionó un registro de las piezas dentarias que presentan reabsorción radicular, y en que grado lo manifiestan. dividió en:

El análisis paleopatológico del individuo se

Determinación de la presencia o ausencia de caries: mediante el análisis macroscópico de las piezas dentarias deciduas, utilizando una lupa Carl Zeiss, modelo Phota-Zusata con un aumento mínimo de 6X y un aumento máximo de 40X; se registró como 1 cuando se presentaba la carie y como 0 cuando había ausencia de ella. La clase de carie se determinó usando la clasificación ideada y publicada por el Dr. G. V. Black en 1908 (Woelfel y Scheid 1998). Además, se determinó el tamaño y la localización de las caries, utilizando la clasificación de Metress y Conway (1975).

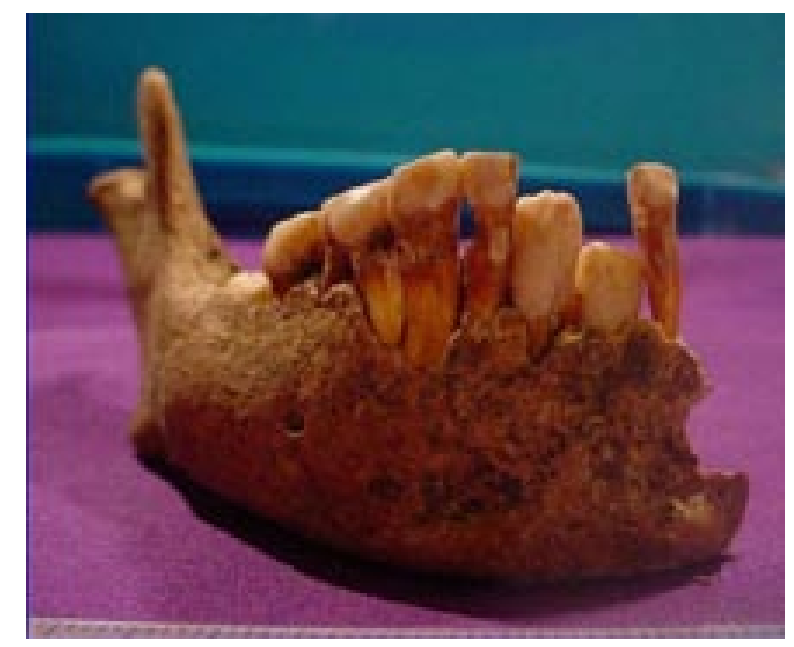

Fig. 2. Parte de la mandíbula y piezas dentales del Individuo $\mathrm{N}^{\circ} 1$.

Determinación de la presencia o ausencia de hipoplasia dental: se observaron los incisivos, caninos y primeros molares permanentes, por medio de una examen macroscópico, utilizando la lupa anteriormente descrita, además se usó una fuente lumínica oblicua respecto a la superficie del diente para acentuar las diferencias en el espesor del esmalte (Trancho y Robledo 2000). Para establecer el tipo de hipoplasia, se utilizó el criterio propuesto por el FDI (World Dental Federation) en 1982, donde se categoriza y clasifica los defectos del esmalte en una escala del 1 al 6 (Tabla 1).

Determinación de abscesos: Se examinó macroscópicamente cada alvéolo dental y se observó la presencia o ausencia de abscesos alveolares y/o inflamación del hueso alveolar. Se registró como 1 cuando existe la patología y como 0 cuando hay ausencia de esta.

Tabla 1. Clasificación de las alteraciones del esmalte según la FDI (1982).

\begin{tabular}{|c|c|}
\hline Clase & Descripción \\
\hline Tipo 1 & $\begin{array}{c}\text { Opacidades del esmalte, cambios } \\
\text { de color a blanco o crema. }\end{array}$ \\
\hline Tipo 2 & Capa amarilla u opacidad marrón del esmalte. \\
\hline Tipo 3 & $\begin{array}{c}\text { Defecto hipoplásico en forma de } \\
\text { agujero, orificio u oquedad. }\end{array}$ \\
\hline Tipo 4 & $\begin{array}{c}\text { Línea de hipoplasia en forma de } \\
\text { surco horizontal o transverso. }\end{array}$ \\
\hline Tipo 5 & Línea de hipoplasia en forma de surco vertical. \\
\hline Tipo 6 & $\begin{array}{c}\text { Defecto hipoplásico en el que el } \\
\text { esmalte está totalmente ausente. }\end{array}$ \\
\hline
\end{tabular}


Determinación de la presencia o ausencia de chipping: se observo las piezas dentales deciduas, utilizando para este fin una lupa Carl Zeiss. Se registró como 1 cuando se presenta y 0 cuando no se presenta.

Determinación de retracción alveolar: la patología se registró según la escala de retracción alvéolar de Luckas (1989), que va desde 0 a 4, siendo 0 ausente y 4 completa.

Determinación del desgaste dental: Este parámetro se observó en cada pieza dentaria decidua, utilizando la escala de desgaste de Molnar (1971). Para este estudio, solo se registró el grado y dirección del desgaste, excluyendo la forma que toma la superficie oclusal debido a este. El grado consiste en una escala del 1-8, donde se agrupa a Incisivos con Caninos y se mide en forma separada de Molares. La dirección del desgaste es una escala del 1-6, donde se valora la orientación del desgaste de la superficie oclusal, con respecto a 2 ejes: BucalLingual y Mesial-Distal.

Para determinar la dieta que consumía el individuo, se utilizaron los siguientes parámetros; desgaste dental, caries y chipping, descritos anteriormente.

\section{RESULTADOS}

De las 27 piezas dentarias examinadas, 11 piezas corresponden a incisivos, de las cuales seis son centrales y las otras cinco del tipo lateral; cuatro piezas del total de la muestra corresponden a caninos, las 12 restantes son molares, ocho de los cuales corresponden a primer molar y cuatro a segundo molar. Del total de las piezas examinadas, 17 de ellas pertenecen a dentadura decidual y 10 a dentadura permanente (Figura 3 y 4).

Las piezas dentales deciduas, que presentaron algún grado de reabsorción de su raíz, fueron: Incisivo lateral inferior derecho, leve; Incisivo lateral inferior izquierdo, leve; Incisivo central superior derecho, leve; Incisivo central superior izquierdo, leve.

De acuerdo al estado de erupción o caída de cada pieza dentaria, y de la reabsorción de la raíz, se establece que la edad del Individuo № 1 , al momento de su deceso, es de 6 años +/- 6 meses.

\begin{tabular}{|lccccc|cccccc|}
\hline Maxilar & $\mathrm{J}$ & $\mathrm{I}$ & $\mathrm{H}$ & $\mathrm{G}$ & $\mathrm{F}$ & $\mathrm{E}$ & $\mathrm{D}$ & $\mathrm{C}$ & $\mathrm{B}$ & $\mathrm{A}$ \\
& + & + & + & + & + & + & + & + & + & + \\
\hline \multirow{3}{*}{ Mandíbula } & $\mathrm{K}$ & $\mathrm{L}$ & $\mathrm{M}$ & $\mathrm{N}$ & $\mathrm{O}$ & $\mathrm{P}$ & $\mathrm{Q}$ & $\mathrm{R}$ & $\mathrm{S}$ & $\mathrm{T}$ \\
& + & + & + & + & - & - & + & + & + & + \\
& & & & & & & & & & & \\
\hline
\end{tabular}

Fig. 3. Piezas dentales deciduas.

-: Pieza ausente. +: Pieza erupcionada.

\begin{tabular}{|c|c|c|c|c|c|c|c|c|c|c|c|c|c|c|c|c|}
\hline Maxilar & $\begin{array}{l}16 \\
\Delta\end{array}$ & $\begin{array}{l}15 \\
\boldsymbol{\Delta}\end{array}$ & $\begin{array}{c}14 \\
\boldsymbol{\nabla}\end{array}$ & $\begin{array}{l}13 \\
\boldsymbol{\Delta}\end{array}$ & $\begin{array}{l}12 \\
\boldsymbol{\Lambda}\end{array}$ & $\begin{array}{l}11 \\
\triangleright\end{array}$ & 10 & $\begin{array}{l}9 \\
-\end{array}$ & $\begin{array}{l}8 \\
-\end{array}$ & $\begin{array}{r}7 \\
\Delta\end{array}$ & 6 & $\begin{array}{l}5 \\
\Delta\end{array}$ & $\begin{array}{r}4 \\
\boldsymbol{\Delta}\end{array}$ & $\begin{array}{l}3 \\
\boldsymbol{\nabla}\end{array}$ & $\begin{array}{l}2 \\
\boldsymbol{\Delta}\end{array}$ & $\begin{array}{l}1 \\
\Delta\end{array}$ \\
\hline Mandíbula & $\begin{array}{l}17 \\
\Delta\end{array}$ & $\begin{array}{l}18 \\
\boldsymbol{\Delta}\end{array}$ & $\begin{array}{l}19 \\
\boldsymbol{\nabla}\end{array}$ & $\begin{array}{l}20 \\
\boldsymbol{\Delta}\end{array}$ & $\begin{array}{l}21 \\
\boldsymbol{\Delta}\end{array}$ & $\begin{array}{l}22 \\
\boldsymbol{\Delta}\end{array}$ & $\begin{array}{l}23 \\
\boldsymbol{\Delta}\end{array}$ & $\begin{array}{l}24 \\
\nabla\end{array}$ & $\begin{array}{l}25 \\
\boldsymbol{\nabla}\end{array}$ & $\begin{array}{c}26 \\
\boldsymbol{\Delta}\end{array}$ & $\begin{array}{l}27 \\
\Delta\end{array}$ & $\begin{array}{l}28 \\
\Delta\end{array}$ & $\begin{array}{l}29 \\
\boldsymbol{\Delta}\end{array}$ & $\begin{array}{l}30 \\
\boldsymbol{\nabla}\end{array}$ & $\begin{array}{l}31 \\
\boldsymbol{\Delta}\end{array}$ & $\begin{array}{l}32 \\
\boldsymbol{\Delta}\end{array}$ \\
\hline
\end{tabular}

Fig. 4. Piezas dentales permanentes.
$\Delta$ : Pieza no presente.
V: Pieza erupcionada.
- Pieza no erupcionada. 
Se observó la presencia de caries en las siguientes piezas: Primer molar superior izquierdo, carie de clase I y tamaño 1; Segundo molar inferior izquierdo, carie de clase I y tamaño 1 . El resto de las piezas dentarias no evidencia caries.

Se determinó hipoplasia dental en las siguientes piezas: Incisivo central superior derecho, lesión de tipo 4; Incisivo central superior izquierdo lesión de tipo 4; Incisivo lateral superior izquierdo lesión de tipo 4; Canino superior izquierdo lesión de tipo 4; Incisivo central inferior derecho lesión de tipo 4; Incisivo central inferior izquierdo lesión de tipo 4.

No se registró la presencia de abscesos dentales ni alvéolares.

Se observó chipping en las siguientes piezas dentales: Incisivo central superior derecho, Incisivo lateral superior derecho, Primer molar superior derecho, Segundo molar superior izquierdo, Primer molar inferior izquierdo.

Existe retracción alveolar en las siguientes piezas dentales: Primer molar superior derecho, Segundo molar superior derecho, Incisivo lateral inferior derecho, Canino inferior derecho, Primer molar inferior izquierdo.

El grado de desgaste dental (Tabla 2), con mayor porcentaje de incidencia, es el de tipo 3, que agrupa al 53\% de las piezas dentales deciduas, lo sigue en escala descendente, el desgaste tipo 2 con un $41 \%$ de incidencia, y con solo un $6 \%$ el desgaste

Tabla 2. Grado de desgaste y dirección de este, en las piezas dentales deciduas.

\begin{tabular}{|l|c|c|}
\hline \multicolumn{1}{|c|}{ Diente } & Grado & Dirección \\
\hline Incisivo central superior derecho & 3 & 2 \\
\hline Incisivo central superior izquierdo & 3 & 6 \\
\hline Incisivo lateral superior izquierdo & 4 & 2 \\
\hline Incisivo lateral superior derecho & 3 & 2 \\
\hline Incisivo lateral inferior derecho & 3 & 6 \\
\hline Incisivo lateral inferior izquierdo & 3 & 6 \\
\hline Canino superior izquierdo & 3 & 2 \\
\hline Canino superior derecho & 3 & 2 \\
\hline Canino inferior derecho & 3 & 3 \\
\hline Primer molar superior izquierdo & 2 & 3 \\
\hline Primer molar superior derecho & 2 & 2 \\
\hline Primer molar inferior izquierdo & 2 & 6 \\
\hline Primer molar inferior derecho & 3 & 6 \\
\hline Segundo molar superior izquierdo & 2 & 3 \\
\hline Segundo molar superior derecho & 2 & 6 \\
\hline Segundo molar inferior izquierdo & 2 & 3 \\
\hline Segundo molar inferior derecho & 2 & 6 \\
\hline
\end{tabular}

tipo 4. Los demás tipos de desgaste dental, no se presentaron.

Los resultados agrupados de los parámetros paleopatológicos analizados, nos indica, que el desgaste dental se presentó en todas la piezas dentales, mientras que el parámetro absceso dental, no se presentó. La retracción alvéolar, chipping y caries, se manifestaron en solo: cinco, cuatro y dos piezas dentales, respectivamente.

Los resultados obtenidos para la determinación de la dieta, revelan que la totalidad de las piezas dentarias, presentan algún tipo de desgaste dental. El chipping, está presente en cuatro piezas dentales y las caries solo en dos piezas, indicando una baja incidencia de estas patologías.

\section{DISCUSIÓN}

La ausencia de piezas dentales, debido al recambio natural de estas, junto con las piezas permanentes presentes y ya erupcionadas o en proceso de formación, dan una edad aproximada de 6 a 7 años. Esto se ajusta a las tablas de erupción y recambio dental de autores como Schour y Massler (1941) y Ubelaker (1996), que calcularon que los incisivos centrales inferiores y los primeros molares, tanto superiores como inferiores, comienzan su erupción entre los $6 y$ 7 años, datos que de igual forma encontraron Logan y Kronfeld (Woelfel y Scheid 1998). Por otra parte, las piezas dentales deciduas, que se encontraban en proceso de caída, presentan una leve reabsorción de la raíz. Según los estudios de Black (Hogeboom 1940), las raíces de los incisivos, deben comenzar su reabsorción a los 4 y 5 años, mientras que los primeros molares, comienzan a los 7 años.

Los resultados obtenidos, muestran que los incisivos centrales y laterales superiores del Individuo № 1 , presentan una reabsorción leve, grado que no coincide con un comienzo de reabsorción a los 4 o 5 años de edad, y además los primeros molares no presentan reabsorción en sus raíces. Esto indica que la edad se ajusta más entre los 6 y 6 años con 6 meses de edad y no a los 7 años como lo propuesto por Schour y Massler (1941) y Ubelaker (1996), debido a que la reabsorción es una etapa importante en el recambio de las piezas dentales, porque a medida que la pieza permanente va formando su corona dental, avanza presionando la raíz caduca, activando la reabsorción de esta. 
Respecto al análisis del estado de salud del Individuo № 1 , este consistió en el estudio de la salud bucal y salud general. Respecto a la salud bucal, se pudo observar una baja incidencia de caries, que se presentaron en forma de pequeñas fisuras en las piezas deciduas, esto quizás se deba a la acción de limpieza que ejerce un tipo de alimentación abrasiva y/o dura (Gaete et al. 2004) y no por una deficiencia de fluoruro en las piezas dentarias. De acuerdo a los estudios de Sealy et al. (1992), las poblaciones de cazadores-recolectores, presentan un alta incidencia de caries, tal vez provocada por la carencia de fluoruro en el agua, que inhibe el desarrollo de estas. Por otra parte puede existir la posibilidad, de que grupos humanos de cazadoresrecolectores, posean una baja incidencia de caries, debido a que tienen una dieta baja en consumo de carbohidratos y/o azucares, con una alta ingesta de carnes o alimentos provenientes del mar (Perez-Perez y Lalueza 1992).

A su vez los grados de desgaste dental que se hallaron, siendo más bien un desgaste medio, se ajustan a los grados de desgaste encontrados en estudios sobre cazadores-recolectores (Scott y Turner 1988), el que fue causado por la fricción normal con los alimentos, que reafirma la posibilidad de que la baja incidencia de caries, sea por un factor alimenticio. No se puede decir que el desgaste es patológico, ya que no hubo exposición de la cavidad pulpar (Luckas 1989).

El chipping o saltaduras del esmalte, que se presentó en algunas piezas deciduas, es producto de la ingesta de alimentos duros y/o abrasivos, o, por el uso de la cavidad oral como herramienta de trabajo (Gaete et al. 2004; Perez-Perez y Lalueza 1992).

Por otra parte, la retracción alveolar observada, se ha clasificado como ligera, esto de acuerdo a la escala de Luckas (1989). Este tipo de retracción nos indica una baja incidencia de enfermedades periodontales, que se contrapone con los resultados obtenidos por Perez-Perez y Lalueza (1992), para grupos de cazadores-recolectores, tanto adultos como infantes, al que pertenecía el Individuo № 1 , donde grandes infecciones bacterianas producen un alto índice de retracción alveolar. La nula presencia de abscesos, concuerda con los índices hallados, para grupos de cazadores-recolectores (Scott y Turner 1988), que nos indica un buen estado de salud oral, que coincide con la ligera retracción alveolar que afectó al individuo, esto porque necesariamente, para que se produzca un absceso dental, debe haber una gran infección periodontal, o un desgaste dental considerable (Brothwell 1987).

En síntesis, los resultados obtenidos para los cinco parámetros dentales, nos muestran una salud bucal buena, donde la incidencia de cada parámetro se presenta en grados muy leves.

En cuanto a la salud general del individuo, esta se midió por la presencia de hipoplasia, donde la lesión se presenta como una línea en forma de surco horizontal o transverso, de carácter leve. Los estudio realizados por Blakey y Armelagos (1985), Goodmann y Rose (1990) y Luckas (1989), en poblaciones arcaicas y modernas, nos indica, que las lesiones en forma de bandas horizontales o transversales, se producen por deficiencias nutricionales o de vitaminas $\mathrm{A}, \mathrm{C}$ y $\mathrm{D}$. En base a esto podemos inferir que el Individuo № 1 , fue afectado durante sus primeros años de vida por algún grado de desnutrición o deficiencia de vitaminas esenciales, ya que los dientes afectados corresponden a la dentadura permanente, que comienza su etapa de formación, durante los primeros años de vida (Kraus et al. 1972; Woelfel y Scheid 1998).

El análisis de la dieta, del Individuo № 1 , muestra que el grado de desgaste dental, en contraposición con la poca presencia de caries, nos indica una dieta con alto componente dulceacuícola, esto concuerda con los estudios de Sealy et al. (1992), que muestran que una dieta marina o dulceacuícola presenta altos índices de fluoruros lo que estaría inhibiendo el desarrollo de las caries, y por otra parte, la presencia de arena y gravilla en estos alimentos, ejerce una acción de limpieza sobre la dentadura. En la baja incidencia de caries, también puede influir el bajo consumo de carbohidratos, aspecto también estudiado por Sealy et al. (1992); Pérez-Pérez y Lalueza (1992) y Littleton y Frohlich (1993). Estos últimos autores comparan a tres grupos humanos que habitaron el Golfo de Arabia, encontraron que un grupo con dependencia altamente marina tenía un desgaste severo, bajos niveles de caries y abscesos dentales, un segundo grupo con una dieta mixta de carne, pescado y agricultura presentaron un desgaste moderado, con baja incidencia de caries y pocos abscesos dentales. El tercer grupo es una población que practica intensamente la recolección 
de alimentos, teniendo un bajo desgaste dental, con una alta incidencia de caries y una severa pérdida de piezas dentales. Frente a esto, el Individuo № 1 consumió una dieta dulceacuícola combinada con frutos y carnes. El chipping encontrado en las piezas dentales deciduas, nos indica una dieta dura, representada por la ingesta de sedimentos incluidos en ciertos mariscos e invertebrados dulceacuícolas.

Comparando los resultados obtenidos para la determinación de la dieta, con los restos faunísticos (Pudú y Zorro), malacológicos dulceacuícolas (Almeja de agua dulce) y vegetacionales, encontrados en el sitio arqueológico Alero Ernesto Marifilo-1 (Adán 2003), se puede inferir que el Individuo № 1 poseía una alimentación mixta, con una abundante presencia de Diplodon chilensis (Almeja de agua dulce), que eran extraídos del actual lago Calafquén. Además esto nos corrobora el desgaste dental y chipping encontrados en las piezas dentales. Esta es una dieta con muchas trazas de sedimentos del lago, combinado con la ingesta de carne de Pudú y Zorro y complementado con frutos, que proporcionaba el ecosistema donde vivió el individuo. Este tipo de dieta, provee al individuo una amplia gama de nutrientes y vitaminas esenciales, que seguramente ayudó al buen desarrollo del sistema inmunológico y óseo del Individuo № 1.

\section{AGRADECIMIENTOS}

A la arqueóloga Leonor Adán, por facilitar los restos óseos del Individuo $\mathrm{N}^{\circ} 1$ y al Doctor Mario Pino, por su ayuda a la realización de este estudio.

\section{BIBLIOGRAFÍA}

ADÁN, L. 2003. Tradición arqueológica de bosques templados en el centro-sur de chile. Poblaciones arcaicas y formativas adaptadas a los sistemas lacustres andinos ( lago Calafquen. Regiones IX y X). Informe final Fondecyt 1010200.

BLAKEY, M y ARMELAGOS, G. 1985. Deciduous enamel in prehistoric Americans from Dickson Mounds: Prenatal and Postnatal stress. Am. J. Phys. Anthropol. 66: 371-380.

BROTHWELL, D.R. 1987. Desenterrando huesos. La excavación, tratamiento y estudio de restos del esqueleto humano. Fondo de Cultura Económica, S.A. de C.V., México, D.F.
BUIKSTRA, J.E. y UBELAKER, D. 1994. Standards for data collection from human skeletal remains. Proceedings of a seminar at the field Museum of Natural History. Fayettevile, Arkansas. Arkansas Archaeological Survey Research № 44.

GAETE, N., NAVARRO, X., CONSTANTINESCU, F., MERA, C., SELLES, D., SOLARI, M., VARGAS, M., OLIVA, D. y DURÁN, L. 2004. Una mirada al modo de vida canoero del mar interior desde piedra azul. Chungará (Arica) 36 supl. espec.: 333-346.

GOODMAN, A.H. y ARMELAGOS, G. 1985. Factors affecting the distribution of enamel hypoplasias within the human permanent dentition. Am. J. Phys. Anthropol. 68: 479- 493.

GOODMAN, A.H. y ROSE, J. 1990. Assessment of systemic physiological perturbations from dental hypoplasias and associated histological structures. Am. J. Phys. Anthropol. 33: 59-110.

HILLSON, S. 1996. Dental Anthropology. Cambridge University Press, Londres.

HOGEBOOM, F. E. 1940. Odontología infantil y dentística sanitaria pública. Cuarta Edición, Hispanoamericana, Buenos Aires.

KRAUS, B., JORDAN, R. y ABRAMS, L. 1972. Un estudio del sistema masticatorio: Anatomía dental y oclusión. Interamericana, México.

LITTLETON, J. y FROHLICH, B. 1993. Fish-Eaters and farmers: Dental pathology in the Arabian Gulf. Am. J. Phys. Anthropol. 92: 427-447.

LUCKAS, J. 1989. Dental Paleopathology: Methods for reconstructing dietary patterns. En Reconstruction of Life from the Skeleton, Editado por Iscan y Kennedy, pp 261-286. Alan R. Liss, Inc., New York.

MENA, F y REYES, O. 2001. Montículos y cuevas funerarias en Patagonia: una visión desde cueva baño nuevo-1, XI región. Chungará (Arica) 33: 21-30.

METRESS, J. y CONWAY, T. 1975. Standardized system for recording dental caries in prehistoric skeleton. J. Dent. Res. 54: 908.

MOLNAR, S. 1971. Human tooth wear, tooth function and cultural variability. Am. J. Phys. Anthropol. 34: 175-190.

PEREZ-PEREZ, A. y LALUEZA FOX, C. 1992. Indicadores de presión ambiental en aborígenes de fuego-patagonia: un reflejo de la adaptación a un ambiente adverso. Anales del Instituto de la Patagonia 21: 99-108.

PINO, M., ADÁN, L. y SEGUEL, O.2004. Geoarcheology of the area of Calafquén Lake, southwestern flank of Villarrica volcano. En Lara, L y Clavero, J, Villarrica volcano 
(39.5으), Southern Andes, Chile. Servicio Nacional de Geología y Minería, Boletín № 61, pp. 61-67.

RODRÍGUEZ, A., GONZÁLEZ, C. y HENRÍQUEZ, M. 2004. Arqueología histórica en la parroquia la Purísima Concepción de Colina: Región Metropolitana. Chungará (Arica) 36: 117-129

SCHINDER, G. y GUICHON, R. 2003. Isótopos estables y estilo de vida en muestras óseas humanas de Tierra del Fuego. Magallania 31: 33-44.

SCHOUR, I. y MASSLER, M. 1941. Development of the human dentition. J. Am. Dent. Assoc. 28: 1153-1160.

SCOTT, R.G. y TURNER II C.G. 1988. Dental anthropology. Ann. Rev. Anthropology 17: 99-126.

SEALY, J., PATRICK, M., MORRIS, A., y ALDER, D. 1992. Diet and dental caries among stone age inhabitants of the Cape Providence, South Africa. Am. J. Phys. Anthropol 88: 123-134.

SILVA, O. 2001. Civilizaciones prehispánicas de América. Séptima edición, Universitaria, Santiago.

TRANCHO, Gy ROBLEDO, B. 2000. Patología oral: Hipoplasia del esmalte dentario. Facultad de Biología. Universidad Complutense Madrid. http://www.ucm.es/info/aep/ boletin/actas/32.pdf

UBELAKER, D.H. 1996. Human skeletal remains, excavation, analysis, interpretation (Manuals on Archeology Series No. 2). Segunda Edición, Aldine Plub., Chicago.

WOELFEL, J. y SCHEID, R. 1998. Anatomía dental: aplicaciones clínicas. Masson, S.A., Barcelona. 
S. MORANO Y S. BUCAREY 